\title{
School Quality and Information Disclosure: Evidence from the Housing Market
}

\author{
Paul Carrillo \\ George Washington \\ University
}

\author{
Stephanie Riegg Cellini \\ George Washington \\ University
}

\author{
Richard K. Green \\ University of Southern \\ California
}

September 2011

\begin{abstract}
In this paper we investigate the relationship between school quality and information disclosure in housing markets. When presented with the option of identifying their local public school in a real estate listing, we find that sellers with homes assigned to higher-performing schools are more likely to provide this information. We find more evidence of selective disclosure in 200102 than in 2006-07, when the costs of gathering and disclosing information on school assignments and quality were higher. Further, we find more evidence of strategic behavior among sellers of large single-family units that presumably appeal to families with children. After controlling for school quality, information disclosure does not appear to impact housing prices. Taken together, our results support the findings of the education literature on the importance of school quality capitalization in residential real estate and they provide the first evidence of strategic information disclosure in housing markets.
\end{abstract}

JEL Codes: L15, I20, R31

Keywords: strategic disclosure, unraveling, education, housing market

* We thank Yongqiang Chu, Dylan Conger, Tony Yezer, seminar participants at the University of British Columbia, and conference participants at the ASSA American Real Estate and Urban Economics Meetings for helpful comments. A previous version of this paper was titled, "Surfing for Scores: School Quality, Housing Prices, and the Changing Cost of Information.” 


\section{Introduction}

Tiebout's (1956) theory tying residential sorting patterns to the provision of local public goods provided the foundation for a large and growing literature assessing the relationship between school quality and housing markets. Many of these studies have used housing prices to directly estimate the monetary value of improvements in student test scores to parents and homeowners. Few, if any, have focused on the role of information in mediating relationships between buyers, sellers, schools, and housing values. ${ }^{1}$ Fewer still have examined the behavior of home sellers and their role in the provision of information on school quality.

This paper takes a step toward filling these gaps in the literature. Building on the "unraveling” theory of information disclosure in the industrial organization literature (e.g., Grossman 1981, Milgrom 1981), we first investigate the behavior of home sellers in revealing information about local schools. We ask whether and how school quality affects the likelihood that a seller will reveal the identity of a property's assigned school in an online real estate listing. Empirical tests of unraveling are rare, as the true quality of a product is typically unobserved: the housing market provides a novel context to test this theory. If sellers selectively reveal information on schools, then information on its own—controlling for school quality—may have an impact on sales prices if the cost to buyers of obtaining information on school quality is sufficiently high.

We explore these issues empirically both in a period where the costs of gathering information are relatively high (years 2001 and 2002) and in a period where these costs are presumably much lower (years 2006 and 2007). Between these two periods, the mandates of the 2001 No Child Left Behind (NCLB) Act, coupled with the growth of the Internet undoubtedly

\footnotetext{
${ }^{1}$ We present a detailed review of the literature in Section II.
} 
reduced the cost of information gathering for potential buyers and perhaps also lowered the costs of disclosure for sellers.

Drawing on Multiple Listing Service (MLS) data of residential sales in Fairfax County, Virginia — the largest suburb of Washington, DC—our results confirm that sellers of units located in high quality school assignment zones are, on average, more likely to disclose the school's identity in an online listing. An increase of just ten points in an elementary school's passage rate on statewide tests increases the likelihood of information disclosure by a sizeable five percentage points in the 2001-02 period—a finding that is robust to a variety of alternative specifications and controls, including the addition of real estate agent fixed effects.

Predictably, selective disclosure appears to be less prevalent in the 2006-07 period when the cost of gathering information on school quality was likely much lower: a ten-point increase in test scores yields a two to four percentage point increase in the likelihood of disclosure. In both periods we observe more selective disclosure for single-family homes and those with three or more bedrooms (presumably families with children) than for smaller units. Our results support the findings of several previous studies (e.g., Figlio and Lucas 2000, Bayer, McMillan, Ferreira 2007) confirming that school quality is much more important in housing transactions involving families with children than for those without

We also investigate the extent to which information disclosure is capitalized in housing prices. Using school fixed effects to control for school quality, we find that information disclosure does not have an independent effect on a home's price. This finding holds for both 2001-02 and 2006-07. It may be that that the relative cost of gathering information about the school for buyers was sufficiently low in both periods that information disclosure on the MLS 
listing was irrelevant, or that buyers do not interpret non-disclosure as a signal of low quality (Fishman and Hagerty 2003).

The remainder of the paper is organized as follows: Section II describes the related literature in both education and industrial organization. Section III presents a conceptual framework and section IV explains our estimation strategy. Section V describes the data, section VI presents our results, and section VII concludes.

\section{Related Literature}

Literature in the economics of education has long emphasized the importance of school quality in housing markets. Tiebout's (1956) theory of residential sorting first suggested that school quality should influence housing prices, and in recent years, a number of studies have quantified these effects. In one strand of literature, Barrow and Rouse (2004), Hilber and Meyer (2004), and most famously, Oates (1969), analyze the capitalization of school spending in housing prices, indirectly estimating the value of school quality to homeowners. A related strand of the literature focuses specifically on student test scores: Bayer, McMillan, and Feirrera (2007), Black (1999), Bogart and Cromwell (1997, 2000), Downes and Zabel (2002), Hayes and Taylor (1996), Kane, Riegg, and Staiger (2006), Weimer and Wolkoff, (2001) and Ries and Somerville (2010) all employ identification strategies based on school assignment zone boundaries to directly estimate the monetary value of improvements in student test scores to parents and home buyers. The results of both strands of literature are remarkably consistent: school quality has a strong positive influence on housing prices. $^{2}$

\footnotetext{
${ }^{2}$ Controlling for socio-demographics across assignment zones (as a proxy for household sorting) in discontinuity designs, Bayer, Ferreira and McMillan (2007), Black (1999), and Kane, Riegg, and Staiger (2006) all find that a one student-level standard deviation increase in test scores raises housing prices by about two percentage points.
} 
A smaller literature has looked at the responses of parents and prices to various forms of information on schools. In work most closely related to ours, Figlio and Lucas $(2000,2004)$ show that, controlling for student test scores, housing prices respond to simplified information on school quality conveyed in school "grades” assigned by the federal government. Further, they find heterogeneous effects by property size, with larger properties (presumably families with children) exhibiting a greater responsiveness to assigned grades than smaller properties (Figlio and Lucas 2000). Drawing on a similar exogenous information shock in Norway, Fiva and Kirkeboen (2011) find a strong, but temporary reaction of housing prices to new information on school quality. Work by Schneider and Buckley $(2001,2003)$ and Hastings and Weinstein (2008) emphasize the role of information and tastes for school quality in parents' choice of schools. Drawing on experimental evidence from Charlotte, North Carolina's school choice program, Hastings and Weinstein (2008) find evidence that when parents are provided simplified information on school quality, they are more likely to choose higher-testing schools for their children. Their results suggest that obtaining information on school quality is costly and interventions that lower these costs have important implications for parental behavior.

In this paper, we assess the impact of information from another angle, asking how school quality influences home sellers' disclosure behavior and how information disclosure in turn influences home prices. Our approach draws on literature in industrial organization. The “unraveling result” (Viscusi 1978, Grossman 1981, Milgrom 1981, and Jovanovic 1982) suggests that, as long as disclosure costs are low, sellers have a strong incentive to voluntarily disclose information about the true quality of their product. The intuition is straightforward: the seller of the highest-quality product has an incentive to disclose information to distinguish his product from the competition. Once the first seller discloses, the seller of the second-best quality 
product has an incentive to disclose, and so on until only the lowest-quality products are left. Therefore, if a seller does not disclose the true quality of his product, rational buyers will assume lower-than-average quality. It follows that sellers of both high- and low-quality products will have an incentive to disclose: the result is full voluntary information provision by all sellers.

In a review of the quality disclosure literature, Dranove and Jin (2010) point out that the unraveling result relies on several strong assumptions. Notably, information disclosure must be costless. Jovanovic (1982) shows that if disclosure costs are positive, the optimal disclosure policy is characterized by a quality threshold: if the quality is below this threshold, the seller will not disclose and vice versa. In the housing market, sellers (or real estate agents) are likely to have at least some minimal cost of disclosing school assignment information, as they typically must look up school assignments and spend a few minutes filling out the MLS listing to include them. We suspect that disclosure costs were lower in 2006-07 than in 2001-02, as Internet access and download speeds increased substantially over this period.

Other key assumptions relevant to our study emphasize the role of buyers. Unraveling may fail if consumers have heterogeneous preferences for quality and/or if products differ on more than one attribute (e.g., quality and location) (Hotz and Xiao, forthcoming). This is undoubtedly the case in housing markets. We therefore examine information disclosure separately for larger and smaller homes that are likely to attract families with similar tastes for school quality. Further, a market may reflect strategic disclosure, rather than unraveling, if at least some unsophisticated consumers do not hold rational expectations about the quality of undisclosed products— that is, do not perceive non-disclosure as a signal of poor quality (Fishman and Hagerty 2003). 
In the empirical literature, a handful of previous studies have analyzed correlations between information listings and the quality of traded products (Mathios 2000, Jin and Leslie 2003, Jin and Sorenson 2006). ${ }^{3}$ They generally find little evidence of unraveling, even when disclosure costs are low. Firms with higher quality products are typically found to be more likely to disclose, although several studies have found that this is not necessarily the case (Dranove and Jin 2010). Direct tests of selective disclosure are rare, because in most cases the true quality of the traded product is unobserved. The housing market provides us with a novel opportunity to perform an empirical test for the presence of selective disclosure.

Finally, we contribute to a line of literature that assesses the value of information. Previous estimates have primarily come from health care markets (Jin and Sorensen 2006, Dranove and Sfekas 2008). We estimate the extent to which school assignment information is capitalized in housing prices, controlling for school quality. Our approach builds on that of Figlio and Lucas (2000, 2004), but rather than assessing the value of information contained in school letter grades (e.g., A vs. B), we assess the value of identifying a property's school assignment.

\section{Conceptual Framework}

In online housing listings, a seller is required to inform the buyer about certain characteristics of her home, such as its age and number of rooms. Other information, including the identity of the home's assigned public elementary school, is voluntarily disclosed. In a market characterized by unraveling, school quality should not affect a seller's decision to reveal the identity of a property's assigned school, since all sellers—regardless of quality—will choose to disclose.

\footnotetext{
${ }^{3}$ See Dranove and Jin (2010) for a review of the empirical literature on unraveling.
} 
In a market characterized by strategic disclosure, school quality will be a determinant of disclosure behavior, but it may not be the only consideration. As discussed above, the seller's costs of disclosure, heterogeneous consumer preferences, and buyers' assumptions about nondisclosure may all play a role. To this list we add one consideration that is implicit, but not clearly articulated in previous literature: the cost to buyers of obtaining their own information on product quality. Information disclosure decisions are only relevant in a setting where quality is essentially private information. That is, when the costs to buyers of gathering their own information are sufficiently high to prevent at least some consumers from gathering information on their own.

All of these factors will not only affect information disclosure, but could also influence the extent to which information is capitalized in housing prices, if at all. If, for example, buyers rationally believe that non-disclosure signals low quality, we would predict a positive price effect for properties for which the seller disclosed school assignment information. In contrast, if the marginal buyer can easily access information on school assignments and quality on her own, we would expect little capitalization.

The theoretical works reviewed above allow us to make a number of predictions. In a period when both sellers' disclosure costs and the costs of information gathering for buyers are sufficiently high, strategic disclosure behavior on the part of sellers will occur. In such a setting, capitalization of information in home prices would be expected, at least for those homes assigned to high-quality schools. Over time, as sellers' disclosure costs decrease and information about school identities and quality becomes more readily available to potential buyers, strategic disclosure as well as information capitalization should be much weaker. 
To test our predictions, we examine effects in two periods that exhibit substantial differences in the costs of gathering information on school quality. In particular, we compare home sales in years 2001 and 2002 to comparable sales in years 2006 and 2007. We hypothesize that the growth of the Internet, coupled with the testing requirements of the 2001 No Child Left Behind (NCLB) Act, reduced both sellers’ disclosure costs and the costs of information gathering for buyers in the later period.

No Child Left Behind was among the most sweeping educational reforms in the history of the United States. The policy required states to develop and implement a program of statewide student testing and school accountability measures. Most importantly, the legislation required that school-level student achievement data be made available to parents and the public beginning in the 2002-03 academic year. Specifically, the legislation required school districts to provide a report card identifying how each school's average test scores compared to others in the district and the state overall (NCLB 2001, Title I, Section 1111 (h)). Further, school districts were required to:

...publicly disseminate the information described in this paragraph to all schools in the school district served by the local educational agency and to all parents of students attending those schools in an understandable and uniform format and, to the extent practicable, provided in a language that the parents can understand, and make the information widely available through public means, such as posting on the Internet, distribution to the media, and distribution through public agencies... (NCLB 2001, Title I, Section 1111 (h)2(E) http://www2.ed.gov/policy/elsec/leg/esea02/pg2.html\#sec1111)

We hypothesize that with these provisions, NCLB substantially lowered the cost of information gathering on school quality for parents and potential homebuyers.

Buyers' information and sellers' disclosure costs between the two periods we examine were also reduced due to a substantial expansion in household Internet access. Among Virginia 
households, Internet penetration rose from 55 percent in 2001 to 73 percent in 2007 (U.S. Census Bureau 2001, 2007), allowing more potential homebuyers to access school quality measures on the web. In addition to posting test scores, district websites also began to include applications that could be used to search easily for the local public school assigned to a particular address.

As noted above, heterogeneous consumer preferences may contribute to selective disclosure. If a seller anticipates that some buyers have a higher willingness-to-pay for school quality, she will be more likely to behave strategically on property listings that appeal to buyers with strong tastes for school quality—presumably, families with children. Because large singlefamily homes will be more likely to attract families with children than small condominiums, we expect the correlation between information disclosure and school quality may be stronger for larger homes. Previous studies confirm substantial heterogeneity in tastes for school quality. Bayer, McMillan, and Ferreira (2007) estimate a much a higher marginal willingness-to-pay for

school quality among families with children than those without. Ries and Somerville (2010) find that after controlling for long-run price trends, only homes purchased by high-income families respond to changes in school quality. Finally, Figlio and Lucas (2000) find a much stronger reaction of prices to information on school quality among larger and single-family homes. We follow the literature in estimating separate models for properties with 0 -2 bedrooms versus 3 or more bedrooms, and attached versus detached units. We describe our methodology further below.

\section{Estimation}

To assess the impact of school quality on the disclosure behavior of sellers, we estimate a linear probability model of the form: 


$$
D_{\text {itza }}=\beta_{1} Q_{i}+\beta_{2} H_{i}+\beta_{3} N_{i}+d_{t}+d_{z}+d_{a}+\varepsilon_{\text {itza }}
$$

where $D_{\text {itza }}$ is the observed disclosure behavior of the real estate agent (or seller), $a$, for transaction $i$, in zipcode $z$, at time $t$. $D_{\text {itza }}$ equals one if the agent discloses information about the property's school assignment and zero otherwise. $Q_{i}$ is a measure of school quality, $N_{i}$ is a vector of neighborhood characteristics and $H_{i}$ is a vector of housing unit characteristics. $d_{t}$ and $d_{z}$ are month-year and zip-code fixed effects, respectively. In our preferred specification, we add real estate agent fixed effects, $d_{a}$ to control for unobserved preferences for disclosure across sellers. $^{4}$

We base our measure of school quality, $Q$, on a seven-year average of student pass rates on standardized exams. The decision to use long-term averages follows from Kane, Staiger, and Samms (2003), demonstrating that rather than responding to annual fluctuations in student test scores, housing markets respond only to long-run trends in student achievement. We compute the school's average passing rate on the state's reading and mathematics tests over academic years 2000-01 to 2006-07. ${ }^{5}$ We describe the data in detail in the following section.

$N$ consists of variables related to neighborhood desirability, such as the population density, proportion minority, and median household income of the census block group. Housing unit characteristics, $H$, include the number of bathrooms, number of bedrooms and age, among others (see Table 1 for the complete list). We also identify whether the unit is a "detached residence,” a “townhome,” or a "multifamily dwelling," in order to better understand potential differences in effects for families with children, as noted above. Finally, in some specifications

\footnotetext{
${ }^{4}$ In all regressions, standard errors are robust to heteroskedasticy and clustered at the elementary school level. Specifications run without clustering yielded extremely similar significance levels and are available on request. ${ }^{5}$ Using test scores from 2000-01 for the 2001-02 real estate sample and scores from 2005-06 for the 2006-07 sample yielded qualitatively similar results.
} 
we include the number of days that a property is on the market, a potentially endogenous variable. It may be important to control for this variable because listings that have been active for longer periods of time may have higher chances of being updated and be more likely to display information about the school identity. To address concerns of the potential endogeneity of this regressor, we estimate all specifications both with and without it.

Other potential endogeneity problems arise due to unobservable differences in the homes and sellers in high- and low-scoring school assignment zones. If these differences are correlated with disclosure behavior then our estimates of equation (1) will be biased. For example, it may be the case that sellers in high-quality school zones have a lower cost of disclosure, since they likely value school quality and are already fully informed about the local schools. However, we argue that the MLS listings that we draw on are most often filled out by real estate agents who have a similar (and fairly low) cost of disclosure for all properties and are more likely exhibit strategic disclosure behavior than homeowners. On the other hand, some real estate agents may be more likely to disclose information than others. We add real estate agent fixed effects to mitigate this bias. Our preferred specification is then identified off of variation in the disclosure behavior of the same real estate agent for properties in the same zip code and month with differing school quality.

To assess whether information disclosure influences sales price, we estimate the following hedonic price regression:

$$
\ln \left(\mathrm{P}_{\text {itas }}\right)=\pi_{1} D_{i}+\pi_{2} H_{i}+\pi_{3} N_{i}+d_{t}+d_{a}+d_{s}+\varepsilon_{\text {itas }}
$$


where $P_{\text {itas }}$ is unit $i$ 's transaction price at time $t$, sold by real estate agent $a$, and assigned to school $s . d_{s}$ are elementary school fixed effects. ${ }^{6}$ This approach allows us to test whether there is an independent effect of disclosure on price, controlling for school quality and any other unobservable characteristics common to school assignment zones.

We might also be concerned that real estate agents who are savvy about information disclosure are also savvy about other dimensions of home sales (e.g., furniture staging) that may be correlated with the transaction price. For this reason, we again include real estate agent fixed effects, $d_{a}$, to control for the unobservable abilities of different agents. Our hedonic regressions are therefore identified off of the variation in the disclosure behavior of the same agent for properties within the same assignment zone. Our identifying assumption is that this variation is purely random, although we acknowledge the possibility that other unobservable determinants of disclosure behavior may be correlated with price.

Drawing on the conceptual framework described above, for both models, we estimate separate equations for the 2001-02 and 2006-07 periods to analyze the effects of the changing cost of information. We also estimate separate equations for sub-samples of detached homes (which we sometimes refer to as "single-family”) and for attached units (i.e., multifamily units and townhomes), as well as units with more and fewer than three bedrooms, to capture potential heterogeneity in the reactions of sellers and prices between units that are likely to appeal to families with children and those that are not. ${ }^{7}$

\section{Data}

\footnotetext{
${ }^{6}$ While middle and high schools may also be important to buyers and sellers, we follow much of the literature in considering only elementary schools (e.g., Black 1999, Bayer, Ferreira, and McMillan 2007).

${ }^{7}$ We combine townhomes with multifamily units, since only 2,203 multifamily units were sold in 2006-07.
} 
Our analysis draws on several different sources of data on Fairfax County, Virginia. The county is located in the northern portion of the state, just outside of Washington, DC. With 1.04 million residents and more than 388,000 housing units, it ranks as the most populous jurisdiction of both the State of Virginia and the Washington metropolitan area (Fairfax County website 2010). Notably, Fairfax County is among the richest and best-educated counties in the United States: it ranked second in median household income in 2008, with 58.5 percent of adults over the age of 25 holding at least a bachelor's degree (Census Bureau 2011). The county consists of one unified school district, with 137 elementary schools and a total enrollment across all elementary, middle and high schools of 165,000 , making it the $13^{\text {th }}$ largest school district in the U.S. (Fairfax County Public Schools website 2010).

Real estate data are drawn primarily from the Multiple Listing Service (MLS)—-the primary outlet used by real estate agents to list home sales across the U.S. We gathered housing sales data from two different periods. ${ }^{8}$ Our first set of data consists of information on all of the more than 37,000 residential real estate transactions in Fairfax County that were listed on the MLS and sold between January 1, 2001 and December 31, 2002. To build our second dataset, we collected data on all of the more than 15,000 residential real estate transactions in the same county that were listed on the MLS and sold between January 1, 2006 and June 30, 2007. In both samples, the data contain information about each unit’s transaction price and detailed property characteristics, such as the number of bedrooms, bathrooms, age, vacancy status, and location (geocode information), as well as time on the market. ${ }^{9}$

Our featured variable is a dummy variable, $D_{i}$, labeled as “Disclosure.” It takes on a value of one for properties where we observe the seller revealing the identity of the assigned

\footnotetext{
${ }^{8}$ We thank Metropolitan Regional Information Systems, MRIS for sharing their listing data with us.

${ }^{9}$ We observe the characteristics of the listing at the time it was sold.
} 
school and zero otherwise. In about two percent of listings the seller listed something other than the identity of the school in the space provided —most typically the phrase "please contact the school board." We code these observations as not disclosing $\left(D_{i}=0\right)$, although counting them as disclosing $\left(D_{i}=1\right)$ does not change our results. ${ }^{10}$

To identify whether the housing unit is a detached home, a townhome, or a multifamily dwelling, we use information from the field "type" on the MLS listing. Detached units and townhomes are directly identified from the definitions on the listing. However, we define that the unit is a "multifamily dwelling" if the property is part of a low-, middle- or high-rise building. ${ }^{11}$

While sellers are required to include certain information on the MLS listing, other characteristics, such as lot size, residence size, and of course, school assignment, are optional and, thus, not always available on the MLS database. To identify the elementary school assigned to each housing unit in our sample, we use recorded addresses and Fairfax County's online “School Boundary Locator” tool (http://www.fcps.edu/boundary/). ${ }^{12}$

We draw on data from Virginia Department of Education (VDE) to construct the measure of school quality described in the previous section. For each school, we calculate the average pass rate on state-wide third and fifth grade reading and mathematics exams for academic years 2000-01 to 2006-07. The tests are used by the state to determine school accreditation as well as measures of Annual Yearly Progress under NCLB (Virginia Department of Education website 2009). We use the seven-year average as our measure of school quality in both time periods following Kane, Staiger, and Samms (2003), as discussed above. However, one-year averages of

\footnotetext{
${ }^{10}$ Available on request.

${ }^{11}$ In the MLS listing, this corresponds to those units whose type is either: “Garden 1-4 Floors”, "Mid-Rise 5-8 Floors", or "Hi-Rise 9+ Floors".

${ }^{12}$ We thank Mike Mantzoros from Fairfax County who helped us automate this process. Also note that school assignments correspond to the 2006-07 academic year. We do not have assignments for 2001-02. Any changes in assignments over this period will introduce measurement error, attenuating our estimates.
} 
third and fifth grade scores (using 2000-01 scores for the 2001-02 sample and 2005-06 scores for the 2006-07 sample) resulted in qualitatively similar estimates. ${ }^{13}$

Finally, we add data on neighborhood characteristics from the US Census Bureau's 2000 Decennial Census. These variables reflect the demographic composition of the census block group where the unit is located. The complete list of variables and their descriptions are presented in Table 1.

Our 2001-02 and 2006-07 databases consist of 37,258 and 15,579 records, respectively. ${ }^{14}$ Descriptive statistics are presented in Tables 2a and 2b for the first and second sample periods, respectively. In our 2006-07 sample, the average transaction price was $\$ 530,800$ with a minimum of $\$ 129,000$ and a maximum of $1,995,000 .{ }^{15}$ Mean transaction prices in 2001-02 were significantly lower at just $\$ 296,000$ : the average price in Fairfax County rose by 79 percent between the two periods. In both samples, most homes sold relatively quickly, although mean marketing time in the 2001-02 sample is less than half of the corresponding value in the 2006-07 period. In both periods, the distribution of marketing time is skewed to the right. For example, while the mean time that a home stayed on the market was close to 50 days in the 2006-07 period, 17 percent of the properties sold in less than one week, and fifty percent sold in less than 33 days. On the other hand, a small number of homes (about 10 percent) stayed on the market for more than four months.

Sixty-eight percent of listings disclosed the school's identity in the 2001-02 sample. In 2006-07, the proportion was slightly higher at 75 percent. Average pass rates on standardized

\footnotetext{
${ }^{13}$ Available on request.

${ }^{14}$ When we add real estate agent fixed effects we lose 1,672 transactions in 2001-02 and 2,633 in 2006-07 because agents that sell only one property in Fairfax County are dropped from the analysis. In an alternative specification (upon request) we include these agents and add a common fixed effect for all of them: our results are unchanged.

${ }^{15}$ To avoid biases in our analysis produced by outliers, we exclude 109 properties that were sold for more than $\$ 2,000,000$.
} 
exams were 83.5 percent and 83.4 percent in the two periods, reflecting a slight difference in the composition of homes sold. Compared with the state average of 79.8 percent passing, the Fairfax County scores reflect the relatively high performance of local schools in this area. ${ }^{16}$ Comparing the test scores of units in which sellers disclosed school information to those that did not reveals the expected relationship_-test scores are slightly higher among the units for which the seller chose to reveal the assigned school.

With the exception of age, the mean characteristics of housing units sold in both periods are quite similar. For instance, in both of our samples a typical home for sale in Fairfax County has three bedrooms, two bathrooms, and one fireplace. In addition, an average home in our sample is located in a U.S. Census block-group where 8 percent of its population is black and 8 percent of the population is older than $65 .{ }^{17}$ There is significant dispersion in the characteristics of neighborhoods. For example, while there are many areas in our sample with virtually no African-Americans or Hispanics living in them, there are several Census block-groups that are populated solely by these members of these subgroups.

\section{Results}

Tables 3a reports the results of the linear probability model specified in equation (1) for the 2001-02 sample. The results reveal a positive and significant relationship between school quality and the probability of the seller disclosing the identity of the unit's assigned school. The sign, significance (at the one percent level), and magnitude of the effect remains remarkably robust as covariates and fixed effects are added in columns 2-5. With the exception of col. 1

\footnotetext{
${ }^{16}$ Author's tabulations of state data on $3^{\text {rd }}$ and $5^{\text {th }}$ grade reading and math pass rates from Virginia Department of Education website (2009).

${ }^{17}$ Notice, however, that the Census variables' statistics are weighted by the number of homes sold in each Census block-group and do not necessarily represent an accurate description of the whole population of Fairfax County. Instead, they describe only those locations where real estate transactions were made.
} 
where we present the unadjusted correlation, the estimates suggest that a ten-point increase in exam pass rates increases the likelihood that a seller will disclose information about the school by about five percentage points. A one standard deviation (7.2 percentage point) increase in test scores would therefore raise the likelihood of disclosure by about 3.3 percentage points, based on our preferred estimates in column 5. Notably, the estimates remain largely unchanged with the inclusion of time on the market in column 4, but drop slightly in magnitude from 5.4 to 4.59 with the inclusion of real estate agent fixed effects in column 5.

Table 3b presents our estimates of the determinants of information disclosure for 2006$07 .{ }^{18}$ In this period, school quality is still significantly positively related to information disclosure, but the estimates are smaller in magnitude_-around four percentage points—in columns 2-4. In our preferred specification including real estate agent fixed effects in column 5, the estimates remain significant but drop substantially to 1.78 percentage points for a ten-point increase in pass rates, or 1.3 percentage points for a one standard deviation increase in scores. These estimates reveal that controlling for real estate agent heterogeneity is an important determinant of disclosure—some agents are more likely to disclose than others. Further, the weaker relationship between the propensity to disclose the name of the assigned school and school quality in this period is consistent with the notion that information was more costly to obtain in 2001-02 than in 2006-07. ${ }^{19}$

Our conceptual framework predicts that if sellers anticipate differences in buyer preferences for school quality, then student test scores should be an important determinant of

\footnotetext{
${ }^{18}$ The correlation between school identity disclosure and the characteristics of the housing unit are likely to be different in the 2000-01 and the 2006-07 samples. For instance, at any significance level we can reject the (joint) null hypothesis that all the coefficients shown on the last column of tables 3a and 3b are the same.

${ }^{19}$ Indeed, the null hypothesis that the correlation between test scores and information disclosure in the 2000-2001 period is greater than the correlation in the latter period can be rejected at conventional significance levels (p-value $=0.059$ ).
} 
information disclosure for properties that appeal to families with children, such as single-family dwellings (detached homes) and larger homes, but not for attached units (multifamily units and townhomes) and those with fewer bedrooms. To test this hypothesis, we estimate separate models by building type and number of bedrooms.

The results of specifications including all covariates and fixed effects (as in specification (5) of Tables 3a and 3b) are presented in Tables 4a and 4b for the 2001-02 and 2006-07 samples, respectively. The first column of these tables shows the marginal effect of school quality on information disclosure for the full sample and each corresponding group. In 2001-02, detached homes and those with three or more bedrooms reveal effect sizes similar in magnitude to the full sample (4-5 percentage points). In contrast, selective disclosure appears less prevalent among smaller and attached units, with effect sizes between 2 and 3 percentage points. In 2006-07, we find similar patterns by number of bedrooms. Effects sizes approach zero and are no longer significant for $0-2$ bedroom units, while units with 3+ bedrooms reveal large and significant effects that are similar in magnitude to the full sample. In the later period, the evidence for attached and detached homes is less conclusive. We find slightly higher magnitudes for attached units, but these effects are not substantively different from those of the detached, and both are only marginally significant.

We view the evidence as suggestive of the idea that sellers consider buyers' willingnessto-pay for school quality when choosing whether to disclose, particularly in the earlier period when the costs of obtaining information on school quality were relatively high. Moreover, the descriptive statistics reported in the right hand columns of Table 4a and Table 4b confirm that this result is not driven by differences in the variability of school quality within these types of 
units. While the average attached unit is in a district with a lower-than-average test score, the dispersion of scores within each sub-sample is quite similar.

As discussed above, disclosure might exert an independent positive effect on the price of housing units. In Table 5, we estimate the specifications denoted in equation (2) for both of our sample periods. The coefficient on the disclosure variable assesses the impact of disclosure on log sales price, controlling for school quality with elementary school fixed effects. We also include real estate agent fixed effects to control for unobservable differences in the capabilities of different sellers, but we caution that other endogenous unobservable characteristics may remain.

We find negligible effect sizes and almost no significant impacts of disclosure on sales prices in both time periods and across all sub-samples in Table 5. Even our largest positive point estimates for attached homes (significant only at the ten percent level in 2001-02) reveal an increase of just 0.5 percent or about $(\$ 1,500)$. For all homes, the point estimates are much smaller, just 0.12 and 0.26 percent in 2001-02 and 2006-07, respectively. Our results suggest that it is school quality itself, rather than information disclosure, that is capitalized in home prices. It may be that a large share of buyers was easily able to find information on school quality on their own in both periods or they simply did not view non-disclosure as a signal of low-quality.

The only significant coefficient is on 0-2 bedroom units in 2006-07, but this effect is negative, suggesting a decline in price in response to disclosure for these small units. It may be that these units are assigned to notoriously poor-performing schools, so buyers who would otherwise not know or care about school quality offer lower prices when the school name is revealed. Further, given the negligible results in all other specifications, it may be the case that 
these types of negative price effects of disclosure for properties assigned to low-quality schools may be counteracting positive effects of disclosure for properties assigned to high-quality schools.

To test this hypothesis, in Table 6 we interact disclosure with several different measures of school quality. For comparison, columns (1) and (4) are the same estimates presented in Table 5 for all homes, for 2001-02 and 2006-07, respectively. Specifications (2) and (5) add the interaction of disclosure and average test score. Specifications (3) and (6) add two interaction terms to the model. The first multiplies disclosure by an indicator that equals one if the assigned elementary school was in the top quintile of the test score distribution. The second does the same for the bottom quintile. Our results reveal no significant effects, no consistent direction, and again extremely small point estimates. The lack of information capitalization does not appear to be driven by differences across high- and low-performing schools.

\section{Conclusions}

As the first to investigate the role of information in the relationship between housing markets and public schools, we draw on MLS real estate listings in Fairfax County, Virginia in 2001-02 and 2006-07. Using a rich set of covariates and fixed effects, we find evidence that real estate agents selectively disclose information on school assignments. Our results confirm results found in several other markets — that "unraveling” may fail to occur, even when the costs of disclosure are low. We also confirm the findings of previous research on school quality capitalization — school quality matters. It matters not only for buyers and in final transactions prices, but also for the strategic behavior of sellers. 
Further, we find that selective disclosure behavior declined over our period of study. We find less evidence of strategic behavior in 2006-07 than in 2001-02. We hypothesize that the introduction of No Child Left Behind in 2001 along with the growth of the Internet reduced the costs of information gathering for the buyer and possibly the costs of disclosure for the seller, making strategic disclosure less likely in the later period.

Our analysis also reveals important differences in the strategic behavior of sellers according to differences in potential buyers' preferences for school quality. We find stronger evidence of selective disclosure for large single-family homes that presumably appeal to families with children than for smaller attached units.

Finally, we ask whether information disclosure is capitalized in housing prices. Controlling for school quality with elementary school fixed effects, we find no significant effects of disclosure on home prices and point estimates very close to zero in both the 2001-02 or 200607 period.

Why do sellers strategically disclose information if prices do not seem respond to disclosure? More research is needed to fully understand this result. One possibility is that sellers may systematically overestimate the cost of obtaining information on school quality. With the growth of the Internet and the increasing availability of school quality data, homebuyers today are much more informed about school quality than in previous decades. Sellers, on the other hand — who typically spend nine years or more in the same home—-have not yet updated their beliefs to reflect the substantial decline in the cost of information over the last decade. Our much weaker findings for selective disclosure in 2006-07 suggest that sellers may be slowly catching on. 
In sum, our findings suggest that real estate agents behave much like sellers in other markets: full voluntary disclosure does not occur and unraveling is only partial at best. In cases like these, typical policy prescriptions involve mandated information disclosure. In this case, however, our price results suggest that requiring school assignments to be reported in MLS listings is unlikely to lead to enhanced efficiency, as information provision has virtually no impact on housing values.

This study takes a first step in understanding the role of information in mediating the impact of school quality on housing prices, but much more research must be done to confirm the findings presented here. Future research should test whether other housing markets, particularly those with lower average income and education than Fairfax County, reveal similar patterns of information disclosure. 


\section{References}

Bayer, Patrick, Fernando Ferreira, and Robert McMillan (2007) “A Unified Framework for Measuring Preferences for Schools and Neighborhoods,” The Journal of Political Economy, 115(4): 588-638.

Black, Sandra E. (1999) “Do Better School Matter? Parental Valuation of Elementary Education.” Quarterly Journal of Economics, 114(2): 577-599.

Bogart, William and Brian Cromwell (1997) "How Much More Is a Good School District Worth?” National Tax Journal,50(2): 215-32.

Bogart, William and Brian Cromwell (2000) "How Much Is a Neighborhood School Worth?” Journal of Urban Economics, 47(2): 280-305.

Census Bureau. 2011. American Community Survey, 2008. http://www.census.gov/acs/www/ Accessed January 14, 2011.

Downes, Thomas A. and Jeffrey E. Zabel (2002) "The Impact of School Characteristics on House Prices: Chicago 1987-1991.” Journal of Urban Economics, 52(1): 1-25.

Dranove, David and Ginger Zhe Jin (2010) "Quality Disclosure and Certification: Theory and Practice.” Journal of Economic Literature, 48(4): 935-963.

Dranove, David and Andrew Sfekas (2008) "Start Spreading the News: A Structural Estimate of the Effects of New York Hospital Report Cards.” Journal of Health Economics, 27(5): 1201-07.

Fairfax County website. 2010. http://www.fairfaxcounty.gov/demogrph/gendemo.htm. Accessed June 5, 2010.

Fairfax County Public Schools website. 2010. http://www.fcps.edu/statis.htm. Accessed June 5, 2010.

Figlio, David N. and Maurice E. Lucas (2004) "What's in a Grade? School Report Cards and the Housing Market.” American Economic Review, 94(3): 591-604.

Figlio, David N. and Maurice E. Lucas (2000) "What's in a Grade? School Report Cards and House Prices.” NBER Working Paper, No. 8019: Cambridge, MA.

Fishman, Michael J., and Kathleen M. Hagerty (2003) "Mandatory versus Voluntary Disclosure in Markets with Informed and Uninformed Customers." Journal of Law, Economics, and Organization, 19(1): 45-63.

Fiva, Jon H. and Lars J. Kirkeboen (2011) "Information Shocks and the Dynamics of the Housing Market.” Scandanavian Journal of Economics, 113(3): 525-552. 
Grossman, Sanford J. (1981) "The Informational Role of Warranties and Private Disclosure about Product Quality.” Journal of Law and Economics, 24: 461-489.

Hastings, Justine and Jeffrey M. Weinstein (2008) "Information, School Choice and Academic Achievement: Evidence from Two Experiments.” Quarterly Journal of Economics, 123(4): 1373-1414.

Hastings, Justine, Richard Van Weelden, and Jeffrey M. Weinstein (2007) "Information, School Choice and Academic Achievement: Evidence from Two Experiments.” NBER Working Paper No. 12995: Cambridge, MA.

Hayes, Kathy J. and Lori Taylor (1996) "Neighborhood School Characteristics: What Signals Quality to Homebuyers?” Economic Review, Federal Reserve Bank of Dallas, QIV: 2-9.

Hotz, V. Joseph, and Mo Xiao (forthcoming) "Strategic Information Disclosure: The Case of Multi-attribute Products with Heterogeneous Consumers.” Economic Inquiry.

Hilber, Christian and Christopher Mayer (2004) "Will Changing Demographics Reduce the Support for Local Public Schools?” Brookings-Wharton Papers on Urban Affairs: 107-133.

Jin, Ginger Zhe (2005), “Competition and Disclosure Incentives: An Empirical Study of HMOs.” Rand Journal of Economics, (36): 93-112.

Jin, Ginger Zhe and Phillip Leslie (2003) “The Effects of Information on Product Quality: Evidence from Restaurants Hygiene Grade Cards.” Quarterly Journal of Economics, (118): 409451.

Jin, Ginger Zhe, and Alan T. Sorensen (2006) "Information and Consumer Choice: The Value of Publicized Health Plan Ratings.” Journal of Health Economics, 25(2): 248-75.

Jovanovic, Boyan (1982) “Truthful Disclosure of Information.” The Bell Journal of Economics, 13(1): 36-44.

Kane, Thomas J., Stephanie K. Riegg, and Douglas O. Staiger (2006) “School Quality, Neighborhoods, and Housing Prices,” American Law and Economics Review, 8(2): 183-212.

Mathios, Alan D. (2000) “The Impact of Mandatory Disclosure Laws on Products Choices: an Analysis of the Salad Dressing.” Journal of Law and Economics, (43)2: 651-677.

Milgrom, Paul (1981), “Good News and Bad News: Representation Theorems and Applications.” The Bell Journal of Economics, (12): 380-91.

The No Child Left Behind (NCLB) Act of 2001 (2001), PL 107-110, http://www2.ed.gov/policy/elsec/leg/esea02/index.html. Accessed December 20, 2010. 
Oates, Wallace E. (1969) "The effects of property taxes and local public spending on property values: An empirical study of tax capitalization and the Tiebout hypothesis.” Journal of Political Economy, 77(6): 957-971.

Ries, John and Tsur Somerville (2010) "School Quality and Residential Property Values: Evidence from Vancouver Rezoning.” Review of Economics and Statistics, 92(4): 928-944.

Schneider, Mark, and Jack Buckley (2002) "What do Parents Want from Schools? Evidence from the Internet.” Educational Evaluation and Policy Analysis, 24: 133-144.

Tiebout, Charles M. (1956) “A Pure Theory of Local Public Expenditures,” Journal of Political Economy, 64(5): 416-424.

Virginia Department of Education website (2009). Testing and Standards of Learning (SOL). http://www.doe.virginia.gov/testing/sol/standards_docs/index.shtml. Accessed November 11, 2009.

Viscusi, W. Kip (1978) “A Note on 'Lemons’ Markets with Quality Certification.” The Bell Journal of Economics, 9(1): 277-79. 


\section{Table 1}

\section{Description of variables}

\begin{tabular}{|c|c|}
\hline Variable & Description \\
\hline & Listing \& Transaction Characteristics \\
\hline Disclosure & Equals one if listing provides information about the school district \\
\hline Price & Transaction price in thousands $\$$ \\
\hline \multirow[t]{2}{*}{ DOM } & Days on the market \\
\hline & $\begin{array}{l}\text { School Quality (Q) } \\
\text { Average pass rate on standarized reading and math tests for grades } 3 \text { and 5, 2000-2007 }\end{array}$ \\
\hline & Housing Unit Characteristics $(H)$ \\
\hline Bedrooms & Number of bedrooms \\
\hline Full Bathrooms & Number of full bathrooms \\
\hline Half Bathrooms & Number of half bathrooms \\
\hline Basement & Equals to one if unit has a basement and zero otherwise \\
\hline Central & Equals to one if unit has central heating and zero otherwise \\
\hline N Fireplace & Number of fireplaces \\
\hline New & Equals one if unit is new and zero otherwise \\
\hline Age & Age of the unit (in years) \\
\hline $\mathrm{HOA}$ & Equals one if property has a home ownership association and zero otherwise \\
\hline Detached & Equals one if unit is a detached home \\
\hline Townhome & Equals one if unit is a townhome \\
\hline \multirow[t]{2}{*}{ Multifamily } & Equals one if multifamily unit \\
\hline & Neighborhood Characteristics $(N)$ \\
\hline Density & Population density in Census Block Group (CBG) \\
\hline Black & Proportion black in CBG \\
\hline Hispanic & Proportion Hispanic in CBG \\
\hline Greater than 65 & Proportion older than 65 in CBG \\
\hline HS dropouts & Proportion of high school dropouts in CBG \\
\hline Unemployment & Unemployment rate in CBG \\
\hline Income & Median household income in CBG (in 1999 thousands \$) \\
\hline
\end{tabular}




\section{Table 2a}

Descriptive statistics: Years 2001 - 2002

\begin{tabular}{|c|c|c|c|c|c|c|}
\hline \multirow{2}{*}{ Variable } & \multicolumn{2}{|c|}{ Full sample } & \multicolumn{2}{|c|}{ Disclose } & \multicolumn{2}{|c|}{ Do not disclose } \\
\hline & Mean & St. Dev. & Mean & St. Dev. & Mean & St. Dev. \\
\hline \multicolumn{7}{|c|}{ Listing \& Transaction } \\
\hline Disclosure & 0.68 & 0.47 & & & & \\
\hline Price & 296.1 & 160.4 & 301.7 & 158.4 & 284.1 & 163.9 \\
\hline DOM & 21.3 & 35.2 & 21.3 & 30.8 & 21.2 & 43.1 \\
\hline \multicolumn{7}{|c|}{ School quality (Q) } \\
\hline Score & 83.5 & 7.1 & 84.1 & 6.9 & 82.3 & 7.4 \\
\hline \multicolumn{7}{|l|}{ Housing unit $(H)$} \\
\hline Bedrooms & 3.23 & 1.01 & 3.29 & 1.00 & 3.11 & 1.04 \\
\hline Full Bathrooms & 2.19 & 0.77 & 2.22 & 0.76 & 2.12 & 0.80 \\
\hline Half Bathrooms & 0.76 & 0.64 & 0.79 & 0.64 & 0.68 & 0.65 \\
\hline Basement & 0.68 & 0.47 & 0.70 & 0.46 & 0.61 & 0.49 \\
\hline Central & 0.92 & 0.26 & 0.93 & 0.26 & 0.92 & 0.27 \\
\hline Fireplace & 0.88 & 0.68 & 0.91 & 0.68 & 0.82 & 0.66 \\
\hline New & 0.03 & 0.18 & 0.01 & 0.11 & 0.08 & 0.27 \\
\hline Age & 22.1 & 14.3 & 22.1 & 13.7 & 22.2 & 15.3 \\
\hline HOA & 0.41 & 0.49 & 0.44 & 0.50 & 0.34 & 0.47 \\
\hline Detached & 0.44 & 0.50 & 0.46 & 0.50 & 0.41 & 0.49 \\
\hline Townhome & 0.38 & 0.49 & 0.39 & 0.49 & 0.37 & 0.48 \\
\hline \multicolumn{7}{|c|}{ Neighborhood (N) } \\
\hline Density & 22.1 & 23.9 & 21.2 & 21.6 & 24.2 & 28.1 \\
\hline Black & 0.08 & 0.08 & 0.08 & 0.07 & 0.09 & 0.09 \\
\hline Hispanic & 0.10 & 0.09 & 0.09 & 0.08 & 0.11 & 0.10 \\
\hline Greater than 65 & 0.08 & 0.06 & 0.08 & 0.06 & 0.08 & 0.06 \\
\hline HS dropouts & 0.08 & 0.07 & 0.07 & 0.07 & 0.09 & 0.08 \\
\hline Unemployment & 0.02 & 0.02 & 0.02 & 0.02 & 0.03 & 0.02 \\
\hline Income & 85.7 & 28.0 & 87.8 & 28.3 & 81.1 & 26.9 \\
\hline Observations & \multicolumn{2}{|c|}{37,258} & \multicolumn{2}{|c|}{25,341} & \multicolumn{2}{|c|}{11,917} \\
\hline
\end{tabular}




\section{Table 2b}

Descriptive statistics: Years 2006 - 2007

\begin{tabular}{|c|c|c|c|c|c|c|}
\hline \multirow{2}{*}{ Variable } & \multicolumn{2}{|c|}{ Full sample } & \multicolumn{2}{|c|}{ Disclose } & \multicolumn{2}{|c|}{ Do not disclose } \\
\hline & Mean & St. Dev. & Mean & St. Dev. & Mean & St. Dev. \\
\hline \multicolumn{7}{|c|}{ Listing \& Transaction } \\
\hline Disclosure & 0.75 & 0.44 & & & & \\
\hline Price & 530.8 & 241.0 & 552.6 & 243.2 & 466.6 & 222.1 \\
\hline DOM & 48.8 & 50.8 & 50.2 & 51.0 & 44.6 & 49.9 \\
\hline \multicolumn{7}{|c|}{ School quality (Q) } \\
\hline Score & 83.4 & 7.3 & 84.2 & 7.2 & 80.9 & 7.3 \\
\hline \multicolumn{7}{|l|}{ Housing unit $(H)$} \\
\hline Bedrooms & 3.34 & 1.05 & 3.45 & 1.00 & 3.02 & 1.13 \\
\hline Full Bathrooms & 2.30 & 0.83 & 2.36 & 0.81 & 2.10 & 0.85 \\
\hline Half Bathrooms & 0.78 & 0.64 & 0.83 & 0.63 & 0.65 & 0.66 \\
\hline Basement & 0.71 & 0.45 & 0.76 & 0.43 & 0.57 & 0.50 \\
\hline Central & 0.94 & 0.24 & 0.94 & 0.23 & 0.93 & 0.26 \\
\hline Fireplace & 0.91 & 0.71 & 0.97 & 0.70 & 0.73 & 0.68 \\
\hline New & 0.02 & 0.14 & 0.01 & 0.09 & 0.05 & 0.22 \\
\hline Age & 26.4 & 15.1 & 26.5 & 14.7 & 26.1 & 16.2 \\
\hline HOA & 0.61 & 0.49 & 0.63 & 0.48 & 0.57 & 0.50 \\
\hline Detached & 0.47 & 0.50 & 0.51 & 0.50 & 0.34 & 0.47 \\
\hline Townhome & 0.39 & 0.49 & 0.38 & 0.49 & 0.41 & 0.49 \\
\hline \multicolumn{7}{|c|}{ Neighborhood (N) } \\
\hline Density & 20.3 & 17.1 & 19.0 & 14.1 & 24.2 & 23.5 \\
\hline Black & 0.08 & 0.09 & 0.08 & 0.08 & 0.11 & 0.11 \\
\hline Hispanic & 0.10 & 0.09 & 0.09 & 0.08 & 0.13 & 0.10 \\
\hline Greater than 65 & 0.08 & 0.06 & 0.08 & 0.06 & 0.08 & 0.06 \\
\hline HS dropouts & 0.08 & 0.08 & 0.07 & 0.07 & 0.10 & 0.09 \\
\hline Unemployment & 0.02 & 0.02 & 0.02 & 0.02 & 0.03 & 0.02 \\
\hline Income & 86.2 & 28.0 & 89.6 & 28.5 & 76.1 & 23.9 \\
\hline Observations & \multicolumn{2}{|c|}{15,579} & \multicolumn{2}{|c|}{11,625} & \multicolumn{2}{|c|}{3,954} \\
\hline
\end{tabular}


Table 3a

Determinants of information disclosure: Years 2001 - 2002

Dependent variable: Disclosure (equals one if listing reveals identity of elementary school)

(1)

(2)

(3)

(4)

(5)

Coef. S.E. Coef. S.E. Coef. S.E. Coef. S.E. Coef. S.E

Score

Log days on market (DOM)

$$
0.807(0.180) * * * * 0.532(0.189) * * * 0.526(0.186) * * *
$$

$0.540(0.184) * * *$

$0.459(0.161)$

Bedrooms

Full Bathrooms

Half Bathrooms

Basement

Central

One fireplace

More than one fireplace

New

Age

Age 2

HOA

Detached

Townhome

Log population density

Black

Hispanic

Greater than 65

HS dropouts

Unemployment

Log median hh income

\begin{tabular}{|c|c|c|c|}
\hline $0.005(0.006)$ & $0.002(0.006)$ & $0.003(0.006)$ & $0.007(0.005)$ \\
\hline $0.006(0.008)$ & $0.011(0.007) *$ & $0.008(0.007)$ & $0.006(0.006)$ \\
\hline $0.024(0.007) * * *$ & $0.028(0.007) * * *$ & $0.025(0.006) * * *$ & $0.014(0.006) * * *$ \\
\hline $0.021(0.015)$ & $0.010(0.010)$ & $0.010(0.010)$ & $0.006(0.010)$ \\
\hline $0.024(0.013) *$ & $0.025(0.011) * *$ & $0.024(0.011) * *$ & $0.009(0.010)$ \\
\hline $0.006(0.015)$ & $0.003(0.010)$ & $0.005(0.010)$ & $-0.007(0.008)$ \\
\hline$-0.011(0.018)$ & $-0.004(0.014)$ & $-0.004(0.014)$ & $-0.012(0.012)$ \\
\hline$-0.482(0.028) * * *$ & $-0.450(0.026) * * *$ & $-0.423(0.025) * * *$ & $-0.123(0.020) * * *$ \\
\hline $0.000(0.001)$ & $0.001(0.001)$ & $0.002(0.001) *$ & $0.001(0.001) *$ \\
\hline $0.000(0.000)$ & $0.000(0.000) * *$ & $0.000(0.000) * *$ & $0.000(0.000) * *$ \\
\hline $0.066(0.012) * * *$ & $0.072(0.008) * * *$ & $0.071(0.008) * * * *$ & $0.038(0.008) * * *$ \\
\hline $0.047(0.031)$ & $0.030(0.023)$ & $0.020(0.023)$ & $0.025(0.019)$ \\
\hline $0.015(0.025)$ & $-0.018(0.018)$ & $-0.018(0.018)$ & $0.007(0.016)$ \\
\hline$-0.004(0.014)$ & $0.015(0.010)$ & $0.017(0.010) *$ & $0.011(0.009)$ \\
\hline$-0.138(0.169)$ & $-0.367(0.120) * * *$ & $-0.377(0.120) * * *$ & $-0.303(0.104) * * *$ \\
\hline $0.034(0.161)$ & $-0.077(0.116)$ & $-0.092(0.117)$ & $-0.020(0.100)$ \\
\hline$-0.079(0.175)$ & $0.148(0.116)$ & 0.116 & 0.113 \\
\hline$-0.140(0.205)$ & $-0.012(0.149)$ & $-0.007(0.149)$ & $-0.050(0.126)$ \\
\hline$-0.076(0.440)$ & $0.527(0.340)$ & $0.482(0.342)$ & $0.622(0.263) * *$ \\
\hline $0.003(0.050)$ & $-0.003(0.038)$ & $-0.004(0.038)$ & $-0.012(0.031)$ \\
\hline No & Yes & Yes & Yes \\
\hline No & Yes & Yes & Yes \\
\hline No & No & No & Yes \\
\hline 37,258 & 37,258 & 37,258 & 35,586 \\
\hline 0.063 & 0.102 & 0.108 & 0.351 \\
\hline
\end{tabular}

Note: All estimates are from linear probability models based on equation (1) in text. Standard errors are robust to heteroskedasticity and clustered at the elementary school level. *, **, ***, denote significance at the 10,5 , and 1 percent level, respectively. 
Table 3b

Determinants of information disclosure: Years 2006 - 2007

Dependent variable: Disclosure (equals one if listing reveals identity of elementary school)

(1) (2) (3)

\begin{tabular}{|c|c|c|c|c|c|c|c|c|}
\hline Coef. S.E. & Coef. & S.E. & Coef. & S.E. & Coef. & S.E. & Coef. & S.E. \\
\hline \multirow[t]{22}{*}{$1.151(0.123) * * *$} & 0.494 & $(0.108) * * *$ & 0.370 & $(0.100) * * *$ & 0.397 & $(0.100) * * *$ & 0.178 & $(0.062) * * *$ \\
\hline & & & & & 0.045 & $(0.004) * * *$ & 0.042 & $(0.003) * * *$ \\
\hline & -0.001 & $(0.007)$ & 0.000 & $(0.007)$ & -0.002 & $(0.006)$ & 0.017 & $(0.006) * * *$ \\
\hline & 0.017 & $(0.008) * *$ & 0.016 & $(0.007) * *$ & 0.014 & $(0.007) * *$ & 0.011 & $(0.006)$ \\
\hline & 0.042 & $(0.009) * * *$ & 0.041 & $(0.008) * * *$ & 0.036 & $(0.008) * * *$ & 0.017 & (0.008) ** \\
\hline & 0.032 & $(0.015) * *$ & 0.025 & $(0.013) *$ & 0.027 & $(0.013) * *$ & 0.005 & $(0.009)$ \\
\hline & 0.023 & $(0.017)$ & 0.025 & $(0.016)$ & 0.021 & $(0.015)$ & 0.024 & $(0.013) *$ \\
\hline & 0.060 & $(0.012) * * *$ & 0.056 & $(0.012) * * *$ & 0.057 & $(0.011) * * *$ & 0.005 & $(0.010)$ \\
\hline & 0.057 & $(0.016) * * *$ & 0.054 & $(0.016) * * *$ & 0.054 & $(0.016) * * *$ & -0.009 & (0.013) \\
\hline & -0.352 & $(0.047) * * *$ & -0.350 & $(0.048) * * *$ & -0.275 & $(0.043) * * *$ & -0.093 & $(0.035) * * *$ \\
\hline & 0.003 & $(0.001) * *$ & 0.002 & $(0.002)$ & 0.002 & $(0.001)$ & 0.001 & $(0.001)$ \\
\hline & 0.000 & $(0.000)$ & 0.000 & $(0.000)$ & 0.000 & $(0.000)$ & 0.000 & $(0.000)$ \\
\hline & 0.029 & $(0.012) * *$ & 0.025 & $(0.012) * *$ & 0.024 & $(0.012) * *$ & 0.019 & $(0.010) *$ \\
\hline & 0.122 & $(0.024) * * *$ & 0.126 & $(0.021) * * *$ & 0.131 & $(0.020) * * *$ & 0.032 & $(0.017) *$ \\
\hline & 0.060 & $(0.023) * *$ & 0.055 & $(0.021) * * *$ & 0.061 & $(0.020) * * *$ & 0.040 & $(0.016) * *$ \\
\hline & 0.015 & $(0.010)$ & 0.007 & $(0.010)$ & 0.007 & $(0.009)$ & 0.010 & $(0.007)$ \\
\hline & -0.166 & $(0.069) * *$ & -0.054 & $(0.079)$ & -0.051 & $(0.079)$ & 0.026 & $(0.071)$ \\
\hline & -0.108 & $(0.139)$ & -0.027 & $(0.115)$ & -0.023 & $(0.108)$ & 0.074 & $(0.066)$ \\
\hline & -0.030 & (0.103) & 0.050 & (0.103) & 0.039 & (0.101) & -0.009 & (0.075) \\
\hline & -0.207 & (0.138) & -0.152 & (0.118) & -0.151 & (0.115) & -0.076 & $(0.080)$ \\
\hline & -0.090 & $(0.463)$ & -0.220 & $(0.458)$ & -0.311 & $(0.425)$ & -0.193 & $(0.213)$ \\
\hline & 0.038 & $(0.031)$ & 0.027 & $(0.026)$ & 0.028 & $(0.026)$ & 0.071 & $(0.021) * * *$ \\
\hline
\end{tabular}

Month-Year FE (23)

No No

Yes

Yes Yes

No No $\quad$ Yes $\quad$ Yes $\quad$ Yes

Zip Code FE (51)

No No No

No Yes

Observations

15,579

15,579

15,579

15,579

12,946

R-Squared

0.038

0.102

0.116

0.131

0.602

Note: All estimates are from linear probability models based on equation (1) in text. Standard errors are robust to heteroskedasticity and clustered at the elementary school level. *, ${ }^{* *},{ }^{* * *}$, denote significance at the 10,5 , and 1 percent level, respectively. 


\section{Table 4a}

\section{Determinants of information disclosure property type:}

Years 2001 - 2002

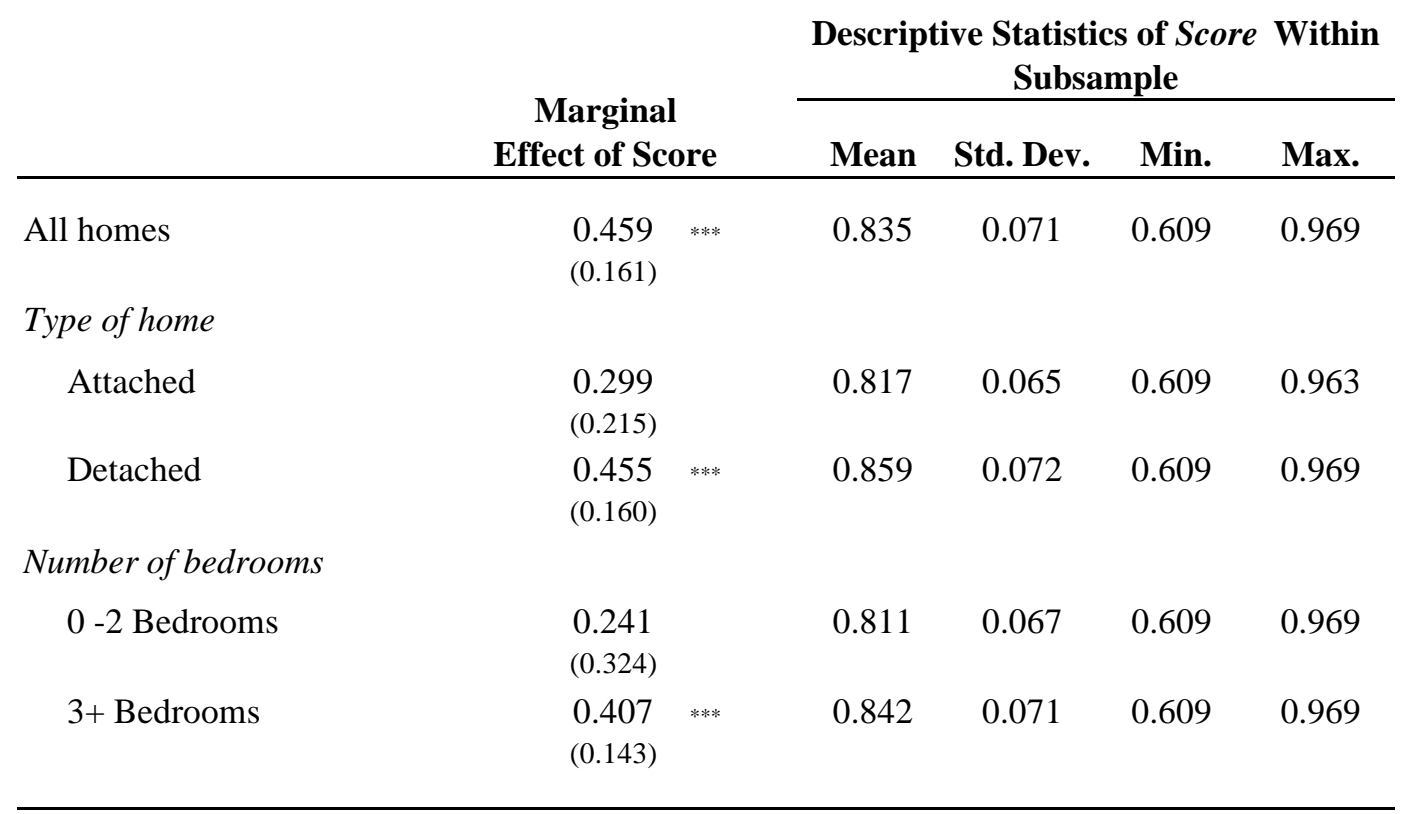

Note: The first column of this table shows marginal effects of the variable Score on the likelihood of disclosing information about the elementary school in a real estate listing. Dependent variable equals one if listing informs about elementary school. All linear probability models include the full set of covariates used in specification (5) of Table 3. Standard errors are robust to heteroskedasticity and clustered at the elementary school level. *, **, ***, denote significance at the 10,5 , and 1 percent level, respectively. 


\section{Table 4b}

\section{Determinants of information disclosure by property type:}

Years 2006 - 2007

\begin{tabular}{|c|c|c|c|c|c|c|}
\hline & \multirow{2}{*}{\multicolumn{2}{|c|}{$\begin{array}{c}\text { Marginal } \\
\text { Effect of Score }\end{array}$}} & \multicolumn{4}{|c|}{$\begin{array}{c}\text { Descriptive Statistics of Score Within } \\
\text { Subsample }\end{array}$} \\
\hline & & & Mean & Std. Dev. & Min. & Max. \\
\hline All homes & $\begin{array}{l}0.178 \\
(0.062)\end{array}$ & $* * *$ & 0.834 & 0.073 & 0.609 & 0.969 \\
\hline \multicolumn{7}{|l|}{ Type of home } \\
\hline Attached & $\begin{array}{l}0.205 \\
(0.109)\end{array}$ & * & 0.815 & 0.069 & 0.609 & 0.958 \\
\hline Detached & $\begin{array}{l}0.159 \\
(0.094)\end{array}$ & * & 0.855 & 0.073 & 0.609 & 0.969 \\
\hline \multicolumn{7}{|c|}{ Number of bedrooms } \\
\hline 0 -2 Bedrooms & $\begin{array}{l}0.001 \\
(0.292)\end{array}$ & & 0.812 & 0.071 & 0.609 & 0.958 \\
\hline 3+ Bedrooms & $\begin{array}{l}0.161 \\
(0.065)\end{array}$ & ** & 0.839 & 0.073 & 0.609 & 0.969 \\
\hline
\end{tabular}

Note: The first column of this table shows marginal effects of the variable Score on the likelihood of disclosing information about the elementary school in a real estate listing. Dependent variable equals one if listing informs about elementary school. All linear probability models include the full set of covariates used in specification (5) of Table 3. Standard errors are robust to heteroskedasticity and clustered at the elementary school level. *, **, ***, denote significance at the 10,5 , and 1 percent level, respectively. 


\section{Table 5}

\section{Determinants of transaction prices}

Dependent variable: Log of transaction price

\begin{tabular}{|c|c|c|c|c|c|}
\hline & \multirow[b]{2}{*}{ All } & \multicolumn{2}{|c|}{ Type of Home } & \multicolumn{2}{|c|}{ Number of Bedrooms } \\
\hline & & Attached & Detached & $0-2$ & $3+$ \\
\hline & (1) & (2) & (3) & (4) & (5) \\
\hline & \multicolumn{5}{|c|}{ Years 2001 - 2002} \\
\hline Disclosure & $\begin{array}{l}0.0012 \\
(0.0027)\end{array}$ & $\begin{array}{l}0.0054 \text { * } \\
(0.0030)\end{array}$ & $\begin{array}{r}-0.0049 \\
(0.0048)\end{array}$ & $\begin{array}{r}-0.0012 \\
(0.0055)\end{array}$ & $\begin{array}{l}0.0005 \\
(0.0032)\end{array}$ \\
\hline Housing Unit Characteristics (H) & Yes & Yes & Yes & Yes & Yes \\
\hline Neighborhood Characteristics (N) & Yes & Yes & Yes & Yes & Yes \\
\hline Month-Year FE & Yes & Yes & Yes & Yes & Yes \\
\hline Elementary School FE (136) & Yes & Yes & Yes & Yes & Yes \\
\hline Real Estate Agent FE $(3,844)$ & Yes & Yes & Yes & Yes & Yes \\
\hline R-squared & 0.927 & 0.918 & 0.869 & 0.919 & 0.906 \\
\hline \multirow[t]{2}{*}{ Observations } & 35,586 & 19,825 & 15,761 & 7,888 & 27,698 \\
\hline & \multicolumn{5}{|c|}{ Years 2006 - 2007} \\
\hline Disclosure & $\begin{array}{l}0.0026 \\
(0.0044)\end{array}$ & $\begin{array}{l}0.0055 \\
(0.0059)\end{array}$ & $\begin{array}{r}-0.0015 \\
(0.0100)\end{array}$ & $\begin{array}{l}-0.0186 * * \\
(0.0094)\end{array}$ & $\begin{array}{l}0.0024 \\
(0.0060)\end{array}$ \\
\hline Housing Unit Characteristics (H) & Yes & Yes & Yes & Yes & Yes \\
\hline Neighborhood Characteristics (N) & Yes & Yes & Yes & Yes & Yes \\
\hline Month-Year FE & Yes & Yes & Yes & Yes & Yes \\
\hline Elementary School FE (136) & Yes & Yes & Yes & Yes & Yes \\
\hline Real Estate Agent FE $(2,550)$ & Yes & Yes & Yes & Yes & Yes \\
\hline R-squared & 0.927 & 0.919 & 0.888 & 0.942 & 0.910 \\
\hline Observations & 12,946 & 6,716 & 6,230 & 2,340 & 10,606 \\
\hline
\end{tabular}

Notes: See Table 1 for descriptions of housing unit and neighborhood characteristics variables. Standard errors are robust to heteroskedasticity and clustered at the elementary school level. *, **, ***, denote significance at the 10, 5, and 1 percent level, respectively. 
Table 6

Determinants of transaction prices: heterogeneity by school quality, all homes

Dependent variable: Log of transaction price

\begin{tabular}{|c|c|c|c|c|c|c|}
\hline & \multicolumn{3}{|c|}{ Years 2001-02 } & \multicolumn{3}{|c|}{ Years 2006-07 } \\
\hline & (1) & (2) & (3) & (4) & (5) & (6) \\
\hline Disclosure & $\begin{array}{l}0.0012 \\
(0.0027)\end{array}$ & $\begin{array}{c}0.0031 \\
(0.0348)\end{array}$ & $\begin{array}{l}0.0040 \\
(0.0037)\end{array}$ & $\begin{array}{l}0.0026 \\
(0.0044)\end{array}$ & $\begin{array}{l}-0.0097 \\
(0.0612)\end{array}$ & $\begin{array}{l}0.0027 \\
(0.0062)\end{array}$ \\
\hline Disclosure * Score & & $\begin{array}{c}-0.0023 \\
(0.0421)\end{array}$ & & & $\begin{array}{l}0.0150 \\
(0.0750)\end{array}$ & \\
\hline Disclosure * Top 20\% & & & $\begin{array}{l}-0.0029 \\
(0.0111)\end{array}$ & & & $\begin{array}{c}-0.0069 \\
(0.0141)\end{array}$ \\
\hline Disclosure * Bottom 20\% & & & $\begin{array}{c}-0.0047 \\
(0.0064)\end{array}$ & & & $\begin{array}{l}0.0043 \\
(0.0117)\end{array}$ \\
\hline Housing Unit Characteristics (H) & Yes & Yes & Yes & Yes & Yes & Yes \\
\hline Neighborhood Characteristics (N) & Yes & Yes & Yes & Yes & Yes & Yes \\
\hline Month-Year FE & Yes & Yes & Yes & Yes & Yes & Yes \\
\hline Elementary School FE (136) & Yes & Yes & Yes & Yes & Yes & Yes \\
\hline Real Estate Agent FE & Yes & Yes & Yes & Yes & Yes & Yes \\
\hline R-squared & 0.927 & 0.927 & 0.920 & 0.927 & 0.927 & 0.927 \\
\hline Observations & 35,586 & 35,586 & 35,586 & 12,946 & 12,946 & 12,946 \\
\hline
\end{tabular}

Notes: See Table 1 for descriptions of housing unit and neighborhood characteristics variables. Standard errors are robust to heteroskedasticity and clustered at the elementary school level. *, **, ${ }^{* * *}$, denote significance at the 10,5 , and 1 percent level, respectively. 